\title{
Path to Promote Tourism Competitiveness of Traditional Villages in the Mountain Area of Central Shandong Province
}

\author{
Lu Haiyong, Hu Haiyan, Miao Lei and Zhou Bo
}

College of Water Conservancy and Civil Engineering, Shandong Agricultural University,

\author{
Taian 271018, China \\ E-mail: Luhaiyong-1@126.com
}

\begin{abstract}
Based on field investigation, the thesis analyzed the characteristics of traditional village tourism resources and existing problems in traditional village tourism in the mountain area of central Shandong Province, and summarized paths to promote tourism competitiveness of traditional village from aspects such as local culture, infrastructure, industry management, featured products, and traditional handicrafts.
\end{abstract}

Key words: Traditional Village; Tourism; Competitiveness; Promote

Located in the middle of Shandong Province, mountain area of central Shandong Province covers an area of about 65,000 kilometers and takes Mount Tai, Mount Lu, Mount Yi, Mount Meng, and Mount Culai as its main body, the surrounding low mountains and hills and the transition zone extends to plain included, serving as the highest terrain in Shandong Province ${ }^{[1]}$. It is generally believed that "it starts with Xiaoqing River and Lubei plain in the north, boarders on hilly areas of Eastern Shandong in the east along the Wei River and Shu River, extends to Mount Ni and Mount Meng in the south, and is adjacent to Luxi Plain with Dongping Lake and Nansi Lake in the west, mainly including Ji'nan, Tai'an, Laiwu, Zibo, Linyi, Weifang, etc.”. More than three fourths of the mountainous region of the province concentrates here in semicircle shape. Surrounded by plains, mountain area of central Shandong Province forms an isolated and typical mesoscale terrain ${ }^{[2]}$.

\section{The General Characteristics of Traditional Village Tourism Resources in the Mountain Area of Central Shandong Province}

Restricted by topography, human activities in the mountain area of central Shandong Province are mainly distributed in middle and low mountain areas with an altitude of 500 to 700 meters or relatively closed geographical environment, thus forming and retaining a large number of traditional villages under relatively complete protection. As of November 2016, 37 villages here have been included in Chinese Traditional Village List, and 91 villages have been listed in provincial traditional village. Compared with traditional villages along Jiaodong Peninsula and Beijing-Hangzhou Grande Canal, though traditional villages here enjoy certain advantages in terms of number, its tourism development is relatively backward and lacks tourism competitiveness, especially in single structures and forms, common product characteristics, as well as small scale benefits, which results from its special geographical environment as well as historical and cultural environment. Most traditional villages are located in remote and inaccessible mountainous areas, which bring some difficulties to tourism development. However, traditional villages possess very obvious tourism advantage compared with plain and coastal areas. If we can correctly understand and solve these problems, it is bound to greatly enhance the further development of traditional village tourism. 


\section{An Analysis of the Weakness of Traditional Village Tourism Competitiveness in Mountain Area of Central Shandong Province}

\subsection{Inadequate Development of Tourism Resources, and Incomplete Industrial Structure}

Despite the fact that traditional village tourism in mountain area of central Shandong Province has some tourism products and various tourism projects, it is stereotyped and enjoys no feature at all, especially in terms of sightseeing, vacation, experience, entertainment and other tourism activities, which are all limited in sightseeing. In terms of cultural tourism resources, most tourism projects provided are rural scenery, delicious food, building communities and so on. Most tourists are photography enthusiasts who often come in holiday period, manifesting evident seasonality. In addition, its tourists are mostly distributed in Shandong Province and its neighboring provinces and cities, have generally low cultural and consumption level, and stay for a short time.

\subsection{Single Tourism Products Structures and Tourists Source}

Tourism projects of traditional village in the mountain area of Shandong Province are single, with sightseeing being its main activity. However, many precious tourism resources here fail to be deeply developed, and its broad and profound cultural connotation fails to be explored. The growth trend of domestic tourists is not obvious, and the rate of return on tourism resources is low. There are more domestic tourists than international ones. Currently, tourists mainly come from Shandong Province, very few of them from overseas. Traditional village tourism in mountain area of Shandong Province remains in, to a certain extent, a original spontaneous state, without forming the parallel development of both China and foreign countries.

\subsection{Lack of Unique Tourism Brand Images}

Traditional village tourism in mountain area of Shandong Province lacks brand image. Tourism images of various traditional villages distribute in "dot" shape, independent with each other, thus limits the impact of tourism brand image. In this case, it is necessary to improve the overall image of traditional village tourism, so as to excavate and integrate resources in a wider range, rather than simply meet the tourists' tourism demand of low level. And it is necessary to promote the development of traditional villages in the whole scenic spot via intra-area overall construction, thus improving and enhancing intra-area brand image.

\subsection{Distinct Peak and Slack Season of Tourism, and Imbalanced Distribution of Time and Space}

Most traditional villages in the mountain area of central Shandong Province are located in remote mountainous areas, and its tourists come here mainly for sightseeing, making the area be limited by both time and space and have distinct peak and slack seasons. Each year, the number of tourists in the six months of April, May, June, August, September, and October accounts for more than 70\% of its annual amount. Tourism peak months mainly concentrate in May and September every year, with the number of arrivals reaching more than one hundred thousand, tens of the number of tourists during slack season. Tourism has imbalanced distribution both in time and space as well. Due to uneven regional development of tourism resources, more tourists concentrate in villages of better development, while few in remote traditional villages, whose tourist flow only accounts for more than $30 \%$ of the annual tourist flow. 


\section{Promotion Strategy for Tourism Competitiveness of Traditional Villages in the Mountain Area of Central Shandong Province}

\subsection{Integrate Local Cultural Resources to Enhance the Cohesion of Tourism Industry}

Local cultural resources are the features and core competitiveness of traditional village tourism development, and also the prerequisite for the sustainable development of traditional villages ${ }^{[3]}$. Nevertheless, many traditional village tourism is only limited in some tourism demands of low level, stimulates economy temporarily to damage the core of traditional village, and has abandoned the core value pursuit of traditional village, which undoubtedly deviates from the value theme of traditional village. Traditional village tourism should start by disseminating and giving play to cultural values, take local education as an important content, and re-build village culture community by restarting the inner impetus of village development, thus inheriting and developing excellent culture $^{[4]}$. First of all, the development of traditional village tourism should focus on traditional production, lifestyle, local customs, and other internal cultural traditions that are necessary foundations for traditional villages to develop tourism, for instance, terrace culture that can reflect the local traditional farming methods, and folk arts manifesting local characteristics; secondly, it is necessary to give full play to the reuse of renovated traditional dwellings, so as to show visitors the farmhouse style of stone house in mountain area, thus creating a warm feeling of "second home" for them; thirdly, it is necessary to emphasize on the participation of local villagers who serve as the main body of local culture. The village committee should guide villagers to actively participate in, and contribute ideas and exert efforts in the protection of cultural heritage and local characteristics, as well as decision-making on tourism development. In addition, it is necessary to organize experts and scholars to arrange the history and culture of villages, in order to keep rural memory and enhance cultural identity and cohesion.

\subsection{Strengthen Infrastructures to Enhance the Support of Traditional Village Tourism}

Currently, most traditional villages have problems in public infrastructure such as unreasonable planning, incomplete auxiliary facilities, and some poor facilities. For instance, there is no tour line for tourists to plan tour; residential wall begins to crack or tilt, which brings security risks to tourists; the hanging signs of "agritainment" are not in line with village scenes; villages lack road signs and introduction of scenic spot image; facilities such as recreation and sports, health and medical service are woefully inadequate; power supply infrastructure is old, and the construction of municipal infrastructures such as drainage, communications, gas, and heating lag far behind; the village road cross-section is relatively narrow and lacks necessary tunnel escape, evacuation site and fire facilities land; domestic sewage is discharged arbitrarily, and environment quality is poor. Therefore, it is extremely necessary to carry out the construction of supporting infrastructures. According to village spatial pattern and on the premise of continuing road texture, the road system inside villages can be improved based on the overall plan, while perfecting water supply and drainage, electric power and telecommunications, gas heating and environmental protection and other public facilities at the same time; reinforce and repair collapsed dwellings, make scientific and rational planning for tourists' tour line inside villages; meanwhile, regulate billboards affecting village appearance, and add road signs and scenic spot introductions in accordance with local environment; rebuild and add service center, parking lot, public toilet, kindergarten, health station and traditional opera square, so as to provide good accessibility for residents, enabling modern living facilities to be adapt to the living needs of residents ${ }^{[5]}$. 


\subsection{Strengthen Industry Management to Improve the Service Level of Traditional Village Tourism}

The development of traditional village tourism ought to be government-oriented and give full play to the government's macro guidance role. Local governments' functional departments at all levels should clarify responsibilities, formulate relevant management measures or regulations, establish perfect and effective management system, standardize and supervise the planning approval and operating management of traditional village tourism, thus guiding it to self-discipline management gradually ${ }^{[6]}$. Residents must possess four licenses at the same time when applying for "agritainment", that is, health license, hygienic license, pre-job training certificate, and business license. Supervision force should be strengthened for the constructed service facilities, including "agritainment", parking lot, and public toilet. Comprehensive evaluation and grade classification can be carried out from aspects such as safety standards, hygiene standards, comprehensive management, reception facilities, and service quality as well, and facilities that do not meet standards shall be delisted or re-regulated. Moderate family hotels can be developed without destroying the daily life of original residents, so as to ensure hardware requirements to carry out tourism. In addition, reception conditions such as accommodation and catering should be improved actively. For example, indoor living standard ought to reach city level, especially bedroom bedding and bathroom facilities in particular shall reach the corresponding standard. In the process of operation, residents should possess not only farmers' simplicity and enthusiasm, but also standardized and star service level.

\subsection{Create Featured Products to Enhance the Attractiveness of Traditional Village Tourism Products}

The building foundation, walls, and various components of traditional dwellings in the mountain area of central Shandong Province are all built by stones. The practice of using local materials fully embodies the philosophy of harmony between man and nature, and has created a distinctive cultural landscape. The unique advantage of traditional village tourism lies precisely in the combination of such cultural landscape and original natural landscape. Therefore, we can develop the strong points and avoid the weak points when planning and develop village tourism of "stone" theme by focusing on stone culture. Link existing tourism resources in village together to form complete ecological chain of stone village tourism by planning and organizing rich as well as colorful stone theme activities $^{[7]}$. In addition, other superior resources also need to be excavated, for example, green food Chinese toon sprouts uniquely owned by mountain area of central Shandong Province, sweet and delicious lanterns persimmon, little cherry, and full-bodied handmade pancakes of rich taste and other local products, all can become tourism products enjoyed by tourists via simple processing or packaging. Various of folk customs and festivals can be launched, such as festival tour, folk custom tour, root seeking tour, and experience tour; eco tour, sightseeing tour, health-keeping tour, and farming experience tour can be carried out on the basis of rural natural beauty, which can enable traditional village to really reflect local characteristics, thus truly achieving the overall planning requirements of "one village one product" "one village one feature", and "one place on view".

\subsection{Integrate Traditional Handicraft Resources to Improve People's Well-being}

Traditional handicraft is an integral part of rural civilization and also the object-creating vein of the Chinese nation that has been inherited for thousands of years. Currently, it is necessary to enable it to shine new vitality in cultural heritage and industrial innovation ${ }^{[8]}$. Combing, recording, and studying traditional handicraft resources in traditional village can effectively complement the current empty-nest phenomenon in villages, and enable some migrant workers to return home for employment, thus enjoying family reunion and having a sense of belonging. The development of 
traditional handicraft can also offer jobs, workshop, and market for villagers. In doing so, villagers secure tangible benefits in increasing wealth, and people's livelihood can be promoted. According to the actual situation of traditional villages, we can develop traditional handicraft in accordance with local conditions, encourage villagers to engage in traditional handicrafts production, establish producers' cooperative for rural handicraft with family workshop as the main body, and enjoy the state preferential policies of fair trade, improving villagers' confidence and pride in the inheritance of traditional handicraft. In addition, village protection requires restoring traditional skills. We can hire local craftsmen to carry out training for traditional skills talents, which can protect traditional handicraft in a rescue manner, enabling endangered traditional handicraft to be inherited and continued.

\section{References}

[1] Lu Haiyong and Hu Haiyan: Chinese \& Overseas Architecture Vo1.9(2016), p. 54-57.

[2] Chen Wentao and Cheng Bin: Construction Science and Technology Vo1.10(2014), p.153-154.

[3] Lin Zurui,Chang Jiang,LiuJie and Tian Mengsi: Modern Urban Research Vo1.6(2016),p.32-38.

[4] Li Huadong: Development of Small Cities \& Towns Vol. 7 (2016), p. 23-26.

[5] Chen Jing, Feng Dan and Yan Yihui: Planners Vol.31 (2015), p.167-172.

[6] Zou Hongxia, Yu Jijing and Yuan Weijuan: Economic Geography Vol. 4 (2009), p. 678-682.

[7] Li Ning and Wang Chuanwu: GuangDong CanYe Vol. 1 (2016), p.43-48.

[8] Information on http://www.panlusheng.com/ 